\title{
Drinking in response to salt injections at different times of day'
}

KEITH OATLEY

UNIVERSITY OF SUSSEX, BRIGHTON, ENGLAND

Drinking tests were carried out on rats at four times of day after NaCl injections of six concentrations. Contrary to what would be expected if a diurnal influence directly modulates the brain mechanisms controlling drinking, there was no potentiation or inhibition of drinking at any of the times when tests were made.

In a previous experiment (Oatley, 1967) it was shown that postdeprivational drinking in rats was a function of the part of the day during which water had been withheld, though the actual time of drinking did not as such affect the amount of water drunk. The explanation seemed to be that diurnal variation in drinking depended on the changing rate of food intake, and that no intrinsic rhythm of drinking exists in rats. The present experiment is a further test of this. Rats were injected with $\mathrm{NaCl}$ at different times of day, and if any diurnal influence bears directly on drinking, either to increase intake during the night or inhibit it during the day, it is likely that rats drinking in response to an osmotic stimulus would exhibit some diurnal variation.

\section{Method}

Subjects were eight naive male hooded rats weighing between 250 and $338 \mathrm{~g}$ and ranging in age from 6-9 months at the beginning of the experiment. Drinking tests were carried out in a battery of cages fitted with burettes as described previously (Oatley, 1967). The experiment was designed to test the drinking response of each animal to a series of injections of $\mathrm{NaCl}$ made at four different times of day. The injections were $2 \mathrm{ml}$ of $\mathrm{NaCl}$ solution IP in concentrations of $0.9,2,3,4,6$, and $10 \%$ by weight in volume. These were administered $30 \mathrm{~min}$ before drinking was allowed; the actual drinking test was of $1 \mathrm{~h}$ duration and was timed to start at 8:00 AM, midnight, 4:00 PM, and noon. There was thus a factorial design with six levels of injection concentration and four times of day, each $S$ being subjected to 24 trials in all. Throughout the period of the experiment a $12 \mathrm{~h}$ light-12 $\mathrm{h}$ dark cycle was maintained in the laboratory, this being a continuation of the regime under which the Ss had been bred and kept. Drinking tests were carried out in the same room as the Ss' home cages. The lighting cycle was timed so that the lights came on at 8:00 AM and went off at 8:00 PM. Ss had food (diet 41B) and water avallable in thelr home cages at all times. The order of presentation of the 24 trials was randomized, though for experimental convenience, all elght rats received each treatment together. After each injection the following times were allowed to elapse before any subsequent trial: after $0.9 \% \mathrm{NaCl}$, at least two whole days; after 2, 3, and $4 \% \mathrm{NaCl}$, at least three whole days; after $6 \%$, at least four whole days, and after $10 \%$, at least five whole days. The rats all survived the several months of this experiment in a healthy state.

Before the experiment proper, the rats were habituated to the procedure (described below) by being injected with $6 \% \mathrm{NaCl}$ and placed in the drinking apparatus on three occasions. In detail, a single treatment was administered as follows: Half an hour before a drinking test was due to start the first $S$ was taken from his home cage, weighed, and given an injection. He was then put in a waiting compartment. This was repeated for the other Ss at 2 min intervals. All eight burettes were then filled with fresh tap water, and a reading of their level taken. Each $\mathrm{S}$ was transferred into a drinking compartment with food available $30 \mathrm{~min}$ after his injection. The first rat thus started his drinking test at the time allotted, but the last did not start until 14 min later. In the case of the 8:00 AM and midnight tests, a small desk lamp was used for the minimum amount of time to allow the essential operations to be carried out. At the end of the $1 \mathrm{~h}$ drinking test each $\mathrm{S}$ was again weighed, put back in his home cage, and the burette reading noted.

\section{Resulis}

The mean drinking scores for the groups of eight rats are shown graphically in Fig. 1. To test whether the time of day of drinking had any significant effect, a factorial ( 6 by 4 ) analysis of variance was performed, using a repeated measures design and removing the between-Ss variation from the analysis. The effect of differing concentrations of $\mathrm{NaCl}$ was found to be significant ( $F=254.0, d f=5 / 161, p<.001$ ), whereas the effect of the time of day of drinking was not $(F=1.9$, df $=3 / 161, p>.01)$. The interaction was significant $(F=2.4, \mathrm{df}=15 / 161, p<.005)$. This somewhat peculiar interaction effect was further investigated by performing repeated measures, one way analyses of variance on the six groups of scores at each of the levels of $\mathrm{NaCl}$. It was found that at $0.9 \%$ $\mathrm{NaCl}, \mathrm{F}=6.02$ and at $4 \% \mathrm{NaCl}, \mathrm{F}=6.84$ (df $=3 / 21$, $p<.005)$. At none of the other levels of NaCl was there anything approaching a significant effect, even at the $10 \%$ level.

Discussion

The normal circadian cycle of drinking as deter- 


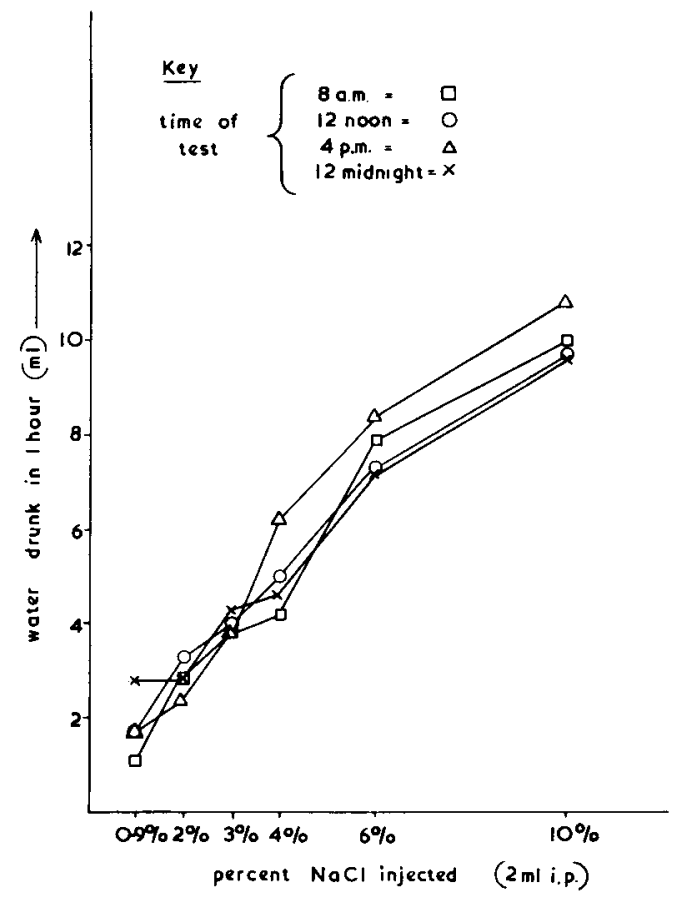

Fig. 1. Mean drinking scores at different times of day following injections of $\mathrm{NaCl}$.

mined by continuous monitoring of rats' ad lib water intake over several days (Oatley, 1965) produces a fairly high intake in the hour after 12 midnight, and also after 4:00 PM, lower after 12 noon, and lowest of all from 8:00 to 9:00 AM. (The time of most drinking is between 4:00 and 8:00 AM, but tests were not made during this period in the present experiment.) Following the control injections of $0.9 \% \mathrm{NaCl}$ there were significant differences between the amounts drunk at different times. Furthermore, the diurnal pattern as seen in the rank order of the observations was the same as that in the ad lib experiment. However, at no level of hypertonic salt injection did this same rank order recur. An interpretation of this is that the osmotic stimulus swamped the rather small diurnal differences in drinking.

One thing is quite clear. There is no evidence of any multiplicative effect on the diurnal pattern. This kind of multiplication can occur, for instance, in the potentiation of drinking at night when rats are not injected or deprived but simply given a preferred fluid like saccharine to drink instead of water (Young \& Richey, 1952). No such accentuation of the pattern was found here; indeed, there was, except for one treatment, ${ }^{2}$ no significant diurnal difference in drinking following an osmotic stimulus. It seems likely that drinking was controlled only by the $\mathrm{NaCl}$ injection, and under the conditions of this experiment diurnal control did not take place.

Though one has to consider the possibility that the injections disrupted the activity of an oscillator generating the rhythm, these results are quite consistent with the hypothesis (Oatley, 1967) that there is no intrinsic rhythmicity of the mechanism controlling drinking. The variations that are observed in water intake are merely in response to alterations of the state of the body fluids, and, from the point of view of a diurnal cycle, the chief agent normally producing these changes is food intake. Whether the pattern of daylight has a direct influence on the brain mechanisms controlling eating is another matter.

\section{References}

OATLEY, $K$. Thirst and drinking mechanisms in the regulation of water intake in rats. Unpublished Ph. D. thesis, University of London. 1965.

OATLEY, K. Diurnal influences on post deprivational drinking in rats. J. Comp. Physiol. Psychol, 1967, 64, 183-185.

YOUNG, P. T., \& RICHEY, H. W. Diurnal drinking patterns in the rat. J. Comp. Physiol. Psychol, 1952, 45, 80-89.

Notes

1. This experiment was carried out at University College, London, and was supported by the Medical Research Council.

2. The single treatment producing deviation from the otherwise null effects of time of day on drinking following osmotic stimulation was that of $4 \% \mathrm{NaCl}$ at 4 p.m. This was different $(\mathrm{p}<0.05)$ from the effects of $4 \% \mathrm{NaCl}$ injected at the other 3 times as shown by a Newman-Keuls test. Unless there is some unrecognized pattern in these results it is probable that this deviation in 1 of 20 hypertonic treatments is of no particular significance. 